\title{
Reading Education of Foreign Literature under the Perspective of Cognitive Poetics
}

\author{
Hong Li \\ School of Foreign Languages \\ Huanghe Science and Technology College \\ Zhengzhou, China
}

\begin{abstract}
In the Chinese education of colleges and universities, foreign literature is one part of Chinese education. Most students have difficulties in reading and understanding foreign literature, which is harder than teaching Chinese literature. Teachers should teach students foreign cultures and writing background in teaching and analysis foreign literature development and writing characteristics in-depth. The author tries to discuss foreign literature teaching under the perspective of cognitive poetics to enhance students' cognition and aesthetic for literature.
\end{abstract}

Keywords - literature education; cognitive poetics; styles and characteristics; reading interest

\section{INTRODUCTION}

For a long time, foreign literature education has always been one of the main constitutions in Chinese institutions of higher learning. With its own unique humane characteristics, the course is conducive to enhance the cultural quality of college students, expand humanistic vision, fully optimize students' personality and of great influence in cultivating students' insight, imagination and innovation ability.

Thanks to the above advantages, Universities cannot simply regard foreign literature as a simple scripted teaching. Foreign literature should not be swallowed by more useful subjects in certain public opinion, Humanism included in the literature can influence things silently and play a role in cultivating students' aesthetic sentiment, enhancing students' concern to world and promoting students to feel and understand life. Under current conditions, the conventional courses only provide 60 class hours for foreign literature in colleges and universities. Teaching so many contents in such a short time to help students to improve their kinds of abilities, 60 class hours is clearly insufficient.

Foreign curriculum for literature couldn't lead college students to read books in depth and then make the appropriate analysis and grasp the meaning of work comprehensively in such a short time. In recent years, in terms of the problem of foreign literature courses in colleges and universities under the current situation, the experts have a research and discussion to improve the current situation. Many experts give a lot of new ideas related to education, such as reader reflecting critics, constructivism and postmodernism. Based on the research and discussion of generations of experts, the author tries to re research the influence of foreign literature education under the perspective of cognitive poetics, hoping to provide a reference for teachers.

\section{OVER VIEW ON COGNITIVE POETICS}

Exploration and discussion on cognitive poetics was from 1970s. Cognitive poetics is not only an analysis method of literature from linguistics and the main feature of the poetics is to concern general propositions of literature discusses basic functions of literature. [1]

Cognitive science involves many fields, such as cognitive linguistics and cognitive psychology. It has made rapid development in Europe and America literature in recent years and has emerged the tide to change research on linguistics and stylistics to explore the cognition in European and American literature world, from the objectivity into the humanities, cognitive poetics was born in such premise.

\section{A. Definition of Cognitive Poetics}

Cognitive poetics was introduced in Towards Cognitive Poetic Theory for the first time. It mainly refers literary criticism theory that combines psychology and neural anatomy to analyze poems in detail. In this book, the author defined cognitive poetics as literary criticism theory.

When writing An Introduction to Cognitive Poetics, the author Cauville said at the very beginning that, "cognitive poetics is the explanation to literature", it is "the deep exploration on literature". In some scholars' opinion, cognitive poetics is "communicating means for literature research and linguistics". [2]

In terms of this point, the current use of cognitive poetics is using its concept, theory to study and appreciate the literature, discuss inner thoughts related to reading the book. In a broad sense, the cognitive poetics is a brand new "poetic" concept of human cognition.

\section{B. Evolution of Cognitive Poetics Theory}

After 30 years of growth and evolution, this theory has got attention from academic fields as a new class of cross-subject theory. Up to now, cognitive poetics theory has basically gone through the following three stages of evolution. 
First of all, take the Towards Cognitive Poetic Theory as the boundary to identify development path of cognitive poetics. Since then many scholars use this theory to discuss works indepth, especially exploration on poetry reading. With change tide of humanism, many theorists explore integration of cognitive linguistics and literature deeply. Thereafter cognitive poetics enter the second development stage.

The generating flag of second phase is Beyond Reason: Practical Guide to Poetic Metaphor. The book advocates using combination of cognitive psychology and cognitive poetics to explore the poetry in literary writings.

Watershed of the third stage is An Introduction to Cognitive Poetics and Cognitive Poetics Practice these two works written by Cauville. They clearly pointed out that readers should read works intensively and advocated analyzing works with related theories such as mental space and signifying.

Domestic research on this concept was still in the start stage. National experts' key research on this theory was still focused on book reading. But along with the improvement of academic ability of experts and diversification of exploring ways, research on this theory will certainly enter a wider exploring area.

\section{To Highlight the Role of Cognitive Poetics in FOREIGN LITERATURE TEACHING}

In terms of the course arrangement of foreign literature in domestic colleges and universities, there is no limit form. Teaching methods on some courses still need to be improved. However, from the teaching reform practice of higher institutions we can notice that the course arrangement of foreign literature shows that they only discuss certain foreign works from the perspective of cognitive poetics but not value the author's experiences. During the teaching, teachers only mention some information of the author but not analyze clearly. One important point in teaching is to pay attention to the related conditions when the author wrote the book. As far as the author of this paper is concerned, the key to achieve real success in foreign literature lies in analyzing the meaning of the course clearly, understanding the teaching goal and implementing it thoroughly.

Cognitive poetics theory stresses on improving creation and reading, and combining creation, reading and self thoughts together. It could not only improve the cognitive level of appreciating foreign literature, but also help to understand creation skills of the author. The combination of creation and reading is conducive to improve students' analysis ability. There is also such occasion in real teaching: some students want to improve self creation ability by learning related theory. But when they begin to write, they will be at a loss because they don' know how to write actually. Especially writing thesis for students in colleges and universities, most students felt hard. Why does this kind of situation appear?

In the author's eye, an important reason is that students don't read enough. They don't understand the subject and contents totally nor grasp connotation in detail. Such situation reduces students' perception insight to the background of the book when reading foreign literature even being a obstacle in practical writing.

In reading education, the author feels that most students have their own understanding on certain situation, but they couldn't apply it flexibly. To make up it thoroughly, students need to be led and supervised by teachers to strengthen their reading on foreign literature. Under the perspective of cognitive poetics, if the students want to improve themselves, the most effective way is reading. Reading famous literary work can make readers feel the deep thoughts connotation and flexible language of the author and get emotional interaction by intensive reading. Classic literature makes readers think and reflect themselves, and help students be more intelligent to reflect their disadvantages more comprehensively.

\section{UNDERSTANDING OF FOREIGN LITERATURE AND APPLICATION OF COGNITIVE POETICS}

In the class of foreign literature, the teaching way is that teachers take up most time of the class. The teaching contents are mainly appreciating foreign literature, literary history, creation background and writing skills. However, when teaching, teachers only mention background, experience and the outline of story but ignore feeling and understanding the works from a deep level. Students are also lack of contrast between reading and themselves. Cognitive poetics stresses spiritual activities while reading and focuses on the feeling and understanding to the works. Only realizing the importance of cognitive poetics to foreign literature teaching can teachers teach the course better and use the theory to file and reform teaching methods. [3]

First of all, teachers can use cognitive poetics to improve students' reading interest to foreign literature. In conventional teaching, students value reciting theoretical knowledge to acquire more points. While facing those complex knowledge points, college students has no interest in deep understanding. Key teaching points of cognitive poetics are intelligence activities, experience and interaction in reading and they put literary aesthetics into daily life to understand. Teachers can use the achievement to guide students to research works and relate it to life cognition. If students can read works with their own experience, their reading interest must be lifted.

Secondly, teachers can use cognitive poetics to improve students' Cognitive memory ability. Memory is the reflection of their experiences by brain. According to storage time of related materials, we can classify memory into sensory memory, short-term memory and long term memory. Psychological and behavioral theory stresses that "when information causes intense mood on people, it may result in the best long-term memory". Cognitive poetics values experience and interaction during reading. In reading experiences, many students are impressed on occasions, roles and understanding. These memories will be called again when someone mentions it. When reading literature, students need guidance from teachers to achieve the harmony between heart and situation so that students can give different analysis based on their own experiences and feelings. Such teaching method helps to turn literary knowledge into long term memory. 
Thirdly, teachers can use cognitive poetics to improve students' literary creation ability. [4]

Literature works are open. Readers have understandings from different perspectives when entering the plots and they even give more connotation than what the author expresses. At the moment, students improve their creativity. When leading students to appreciating the text of foreign literature, teachers should ask students reprocess the text according to imaginary situation built by the author, combine their self experiences and reflections on life. After analyzing author-worksapperception the three stages, students can have a taste of inner connotation of the text, and improve comprehensive appreciating ability on humanities.

Finally, teachers can use cognitive poetics to improve students' literary appreciation. Foreign literature is one essentially humanistic discipline. Under the perspective of cognitive poetics, literature has the functions of education, entertainment and cognition. Scholars mention that "literature can make the readers get rid of reality, or enhance its intellectual acumen and emotional understanding in order to enrich life". Focusing on mental behavior of students in reading, establishing the contact between reading related works and general cognition through the appreciation of foreign literature to enable students to understand the truth, percept life and finally enhance the aesthetic ability.

\section{CONCLUSION}

Foreign literature shows colorful exotic culture for college students. It displays the living conditions of people in Europe and America as well as the cultural background between the lines. When reading these books, students can feel the charm of words, meanwhile, they can also understand the culture and the spirits with their own feelings and thoughts, so cognitive poetics provides theoretical basis for scholars to explore foreign literature. Students can read foreign literature works intensively referring to the cognitive poetics theory, understand the profound connotation and grasp humanistic spirits contained in the text, so that students can enjoy reading when earning the course.

\section{REFERENCES}

[1] Jia Yande. Contrast research on Differences between Chinese and western culture[M]. Shanghai: Shanghai Foreign Language Education Press, 2006.

[2] Jia Qiong. Analyzing modern grammar sentence structure with semantic orientation[J]. language planning, 2013 (29)

[3] Feng Guangyi. Contextual adaptation[M]. Wuhan: Hubei Education Press, 1999.

[4] Hu Min. Research on writing teaching based on exchange context[J]. language planning, 2014 